\title{
Sense of coherence; work and family stressors in a metropolitan municipality in South Africa
}

\author{
Abe, Ethel Ndidiamaka \\ Abe, Isaac Idowu \\ School of Management, IT \& Governance \\ University of KwaZulu-Natal, South Africa
}

\section{Keywords}

Sense of coherence, work stressors, family stressors, work-life balance, work-family benefits, workplace strategies.

\begin{abstract}
Background: Not much information is available on the level of the sense of coherence (SOC) of the working population in South Africa. SOC is the disposition of an individual to accept strain as one of the factors that fosters growth and maturity. It develops from infancy through adolescence from the resources available to an individual and could deplete through stressors. Work stressors are those elements in the workplace that could result in harmful behaviour patterns and stress-aversive reactions. While family stressors are those elements in the domestic environment that engender strain and counterproductive behaviour in individuals.

Aim: The main aim of the article was to examine the association among SOC and work and family stressors among professional level employees in the South African Public Service. The objectives of this article are (1) to ascertain if the professional level employees investigated had strong or weak sense of coherence (SOC) and (2) To determine the effect of work and family stressors on SOC.

Setting: The study was conducted among professional level employees and top management of a municipality in the South African Public Service.

Methods: In this pragmatic, cross-sectional study design, a sample of 307 professional level employees born during the apartheid era in South Africa completed the 13-version Orientation to life Questionnaire (OLQ), work stressor and family stressor questionnaires as well as an elementary demographic questionnaire. Additional data was collected from the interview of 11 other top management members.

Results and conclusion: The findings refuted the claims that unfavourable environmental conditions could affect the development of a strong SOC in an individual by revealing that professional level employees at the South African Public Service generally had strong SOC. It further revealed that the respondents in comparison with the family stressors were experiencing much work stressors. The findings have implications for workplace practices and management of work and family stressors.
\end{abstract}

Corresponding author: Abe, Ethel Ndidiamaka

Email addresses for corresponding author: ethelabe@gmail.com

First submission received: 22 $2^{\text {nd }}$ January 2018

Revised submission received: $27^{\text {th }}$ March 2018

Accepted: 21st May 2018

\section{Introduction}

Work and family stressors capable of affecting an individual's sense of coherence are on the increase among the working populace. In addition to this, professional level employees at the South African Public Service; are bequeathed with an institutional legacy from the apartheid government and saddled with the responsibility of assisting the democratic government in correcting some of the numerous injustices of the apartheid regime. The policies of the apartheid government were generally discriminatory and largely separated the black and the coloured population of South Africa (May \& Govender, 1998; 2004; Özler, 2007). Among the black population, poverty was rated at 68\% (May \& Govender, 1998; Ozler, 2007). In those days, children were neither shielded from the violence at home nor the larger community. They were exposed to hunger, irregular feeding and poor education (May \& Govender, 1998). The consequences of the foregoing conditions could have had adverse influence on the 
development of strong sense of coherence among children and adolescents born and nurtured in those days.

Antonovsky $(1993,1991,1987)$ reports that a sense of coherence is developed through available social support and good living conditions of an infant (Mattila, Rautava, Honkinen, Ojanlatva, Jaakkola et al., 2011). This study assumes that because of the ills of apartheid, children born and raised in those days have weak SOC. Most employees at the professional level of employment in the South African Public Service were born and raised during the apartheid era. At the workplace, in addition to the effects of apartheid, these employees are faced with challenges emanating from the underperformance of governance, incessant structural changes in administration, reforms in local government, territorial changes and novel ways of measuring performance and delivering service to citizens (Cameron, 2005). And at the family domain, they contend with family- related stressors like parenting, need to care for dependant relatives, child care, consequences of HIV/AIDS pandemic, substance/alcohol challenges and relational issues (Azeem \& Akhtar, 2014; Tavora, 2012; Voydanoff, 2004). These situations are all stressful.

SOC has been proposed as one of the internal resources that assists an individual in handling stressors (Feldt, Leskinen, Kinnunen \& Ruoppila, 2003; Nielsen \& Hansson, 2007; Richardson \& Ratner, 2005). The way in which individuals respond to stress show the strength of their SOC; i.e., whether it is weak or strong. Depending on the strength of an individual's SOC, social support, work-life benefits and/or personal internal resources (Abe, 2016) can be used in addressing stressors. Scholars report that individuals having strong SOC (an internal personal resource) cope better with stressors (Diraz, Ortlepp \& Greyling, 2003; Du Toit, 2002). Literature reveals that weak SOC among employees facing high levels of work and family stressors could lead to counterproductive behaviours (Hershcovis, Turner, Barling, Arnold, Dupré et. al., 2007). The conservation of resources (COR) model underpinned the examination of the interplay among SOC and work and family stressors in this article.

Data collected from professional level employees at a metropolitan municipality in the South African public service were analysed to establish if (1) the employees had weak or strong SOC, (2) to determine whether the apartheid era and its adverse conditions had any significant effect therein and (3) to ascertain if the participants were faced with work and family stressors.

\section{Review of important concepts to this study}

This section presents the review of relevant literature on SOC, and work and family stressors to prevent any misperception with respect to the focus of this article.

\subsection{Sense of Coherence (SOC)}

SOC has been described as a mental resource acquired by a person from infancy through adolescence (Antonovsky, 1987; Rivera, García-Moya, Moreno \& Ramos, 2013) which assists the person in coping with stressors (Sarenmalm, Browall, Persson, Fall-Dickson \& Gaston-Johansson, 2013). It is a general disposition of a person to appraise the world from three typical components viz,

1) Meaningfulness (a view that stressors are significant challenges which should be exploited), 2) manageability (the notion that the individual has adequate means of tackling challenges present in the environment) and 3) comprehensibility (a perception that an individual's environment could be explained, arranged and predicted) (Kivimäki, Feldt, Vahtera \& Nurmi, 2000).

The SOC concept takes cognisance of upbringing and a nurturing environment as the source of a strong or weak SOC. Some of the examples of resources that develop SOC are riches, strong character, ethnic constancy, plus communal assistance (Holmberg, Thelin \& Stiernström, 2004). The scholars also found that stressors strongly and negatively influence an individual's SOC. Given the historical background of South Africa and the consequences of protracted years under apartheid, most children and adolescents in those days were not exposed to the resources that could build strong SOC (May \& Govender, 1998). This article assumed that the professional level employees investigated might have weak SOC.

Antonovsky (1987) claimed that the SOC level grows because of an individual's experiences all through infancy, adolescence and youth and stabilises after the attainment of 30 years. Nevertheless, empirical findings demonstrate that SOC develops throughout a lifetime (Eriksson \& Lindström, 2007; Moksnes, Rannestad, Byrne \& Espnes, 2011). Empirical research also found that SOC had an inverse 
relationship with stress and that continued exposure to stressors causes SOC to deteriorate (Moksnes et al., 2011; Wolff \& Ratner, 1999). Kinman (2008), in a study among academics in the UK, found that statistically significant associations were found among SOC, job stressors and health outcomes. The scholar confirms Eriksson and Lindström's (2005) suggestion that mean SOC at 30.66 is a pointer that sample respondents have strong SOC. Strümpfer et al. (1998) Observe that satisfaction with work correlated positively with SOC among a sample of 323 individuals selected from nurses, skilled workers and management staff. But there is a scarcity of studies that examined SOC and its interface with work and family stressors.

\subsection{Work Stressors}

Job stress, absence of autonomy and function vagueness/role conflict are the work stressors examined in this article and presented below.

2.2.1 Job stress

Some authors have used job stress to explain those factors in the work environment that impact negatively on individuals (Beehr, 1976; French \& Caplan, 1972; Kahn, Wolfe, Quinn, Snoek \& Rosenthal, 1964). Others described job stress as; overall body reaction to any need (Selye, 1975), excess demand in an environment that portends to threaten an individual's abilities and resources to manage it (McGrath, 1976), and danger to the individual as a result of the features of the work environment (Caplan, Cobb, French et al., 1975). Yozgat, Yurtkoru and Bilginoglu (2013), citing Beehr and Newman (1978: 670), define job stress as a situation wherein job-related factors interact with a worker to change (i.e. disrupt or enhance) his or her psychological and/or physiological conditions such that the person (i.e. mind and body) is forced to deviate from normal functioning. There is evidence that the more the imbalance among needs and a person's capacity, the more they felt job stress (Jamal, 2005). Hosie and Sevastos (2010), and Warr (2007) submit that stress emanating from work could affect an individual employee's mental health and physiological wellness. This article appraised job stress as those situations that place an individual employee in a position where he/she is ill disposed to perform his/her function maximally because of strain resulting from the job and/or work environment. Job stress could associate negatively with SOC and persistent job stress could negatively affect strong SOC on the long run.

\subsubsection{Absence of autonomy}

Parker, Axtell, and Turner (2001) refer to job autonomy as the discretionary level that employees can make decisions with respect to important issues about their work. Such decisions may include time and ways of performing one's tasks at the workplace. Absence of autonomy refers therefore to the lack of discretion to make important decisions concerning one's job (Kim \& Stoner, 2008; Liu, Spector \& Jex, 2005). Similarly, Thompson and Prottas (2006) refer to job autonomy as the level of freedom and discretion to arrange the flow of work and make decisions as to the method of performing a job, inherent in that job (Hackman \& Oldham, 1976). Absence of autonomy could have a significant impact on the level of an individual's SOC. Liu et al. (2005) report that felt autonomy associated positively with satisfaction (at personal and organisational levels). This article presumes that job autonomy could improve an individual employee's SOC and conversely reduce stress associated with absence of autonomy. Absence of autonomy could task an individual's SOC by reducing its strength.

\subsubsection{Function vagueness/role conflict}

Unarguably, diverse and clashing sources of governmental influences cause significant function vagueness to employees in the Public Service (Pandey \& Wright, 2006). Features of such organisation, for example, centralised decision making hierarchies (House \& Rizzo, 1972; Morris, Steers \& Koch, 1979; Nicholson \& Goh, 1983), and formalities (Ramaswami, Agarwal \& Bhargava, 1993), are reported to heighten function vagueness. A study conducted by Erera (1989) at the local Department of Social Services in New York, reports that practices and policies adopted by the government at the state level was responsible for function vagueness among middle level professionals. The managers in that study reported that the reason for this vagueness was attributable to ambiguity, constant changes in governmental policies and irrelevance (Pandey \& Wright, 2006). Hamner and Tosi (1974) report, that function vagueness is an outcome of the absence of necessary information concerning what an individual's task is. 
Scholars believe that the effect of function vagueness and role conflict on behaviour patterns and attitudes associated with work is all-encompassing (Netemeyer, Johnston \& Burton, 1990; Jackson \& Schuler, 1985; Fisher \& Gitelson, 1983). This article assumes that function ambiguity and role conflict are stressors capable of adversely affecting an employee's SOC. This could result in individuals with strong SOC using it to address stressors and on the long run, depleting their SOC.

\subsection{Family Stressors}

The family is among the most influential element in childhood that fosters coping abilities and shapes a child's orientation to life (Butters, 2002; Merikangas, Dierker \& Fenton, 1998). Antonovsky (1987) posits that resources available in the family build up an individual's SOC from infancy through adolescence. These resources shape the individual's ability to meaningfully comprehend and manage stressors in life. Antonovsky (1987) and Butters (2002) agree that the character of the environment in which a child is raised influences the way in which the individual perceives strain/stress. Similarly, Moos (2013) reports that events that occur in childhood through developmental stages help shape the individual's outcome in later life. This implies that the family could be a source of SOC-building resources or the source of SOC-depleting elements (stressors).

Family stress is characterised by multifaceted need for modification or adaptation in behaviour (McCubbin \& Sussman, 2014). Aseltine Jr, Gore, and Gordon (2000) Confirm that family stressors could have negative influence on a person's internal consistency. According to Hepburn and Barling (1996) in Jones, Burke and Westman (2013), responsibility for providing care for elders could upset work schedules, lead to fractional absenteeism and cause disruptions at work.

Depending on the type of family, most individuals facing problems with their children, elder relations needing care, relational tension and absence of spousal support may have difficulty coping at home and at work. This article suggests that the foregoing could negatively influence an individual's SOC.

\subsection{Theoretical framework}

The theoretical context of this article on the interface between SOC and work and family stressors at a municipality in the South African public service is presented in this section. Based on Hobfoll 's (1989, 2001, 2011a, 2011b) conservation of resources (COR) theory.

2.4.1 Conservation of Resources (COR) theory

According to scholars, people look for balance among challenges (strains) and resources by seeking for ways of bringing down the rate of demands (strains) and/or finding ways of increasing resources (means) in order to be able to manage present strains (Hobfoll, 1989, 2001, 2011; Shore , 1996). COR theory predicts that the major determinant variable in stress development is the loss of resources (Hobfoll , 2001). The prediction of this theory is that stress is inevitable where resources are perceived to be vulnerable, lost, forfeited and uneven, or, if people as individuals or groups are unable to see the way of enhancing and securing their resources either by personal or collaborative efforts. Stress occurs: a) while a person's resources are under the threat of loss, b) when a person's resource gets lost, or c) if people are unable to gain enough resources from a major outlay (Hobfoll , 2001).

COR theory is a major theory in the study of burnout (Brotheridge \& Lee, 2002; Buchwald \& Hobfoll , 2004; Freedy \& Hobfoll, 1994; Freedy, Hobfoll \& Ribbe, 1994; Neveu, 2007) and difficult work situations (Halbesleben \& Bowler, 2007; Jawahar, Stone \& Kisamore, 2007; Zellars, Perrewé, Hochwarter \& Anderson, 2006). The theory is tenet-based; some of the tenets are;

Tenet 1 the supremacy of the loss of resource: This tenet suggests that the loss of resource is unduly more important than the gain of resource. It considers that the effect of loss of resource is not only disproportionate in the aspect of levels but also rapidity (Hobfoll, 2011).

Tenet 2 Resource investment: assumes that individuals with more resources are least threatened by the loss of resources and most capable of reinventing resource gain. In this article, an individual with strong SOC may have a lesser perception of the impact of work and family stressors, and would use work-life balance strategies in place at the municipality to boost SOC.

Tenets 3 and 4: Resource loss and gain: posit that the cycle of gaining or losing resource happens in continuously stressful situations, if the organisation and people lack resources, and if a main stressful event happened. These cycles increase with more power and rapidity as people, units, and establishments 
either gain resources to exploit novel challenges or lose the resources required to solve problems. This implies that an individual can lose resources to cope with stressors or achieve satisfaction. According to Hobfoll (2011), family and work competitively make demands on the resources available to individuals and the degree to which resources are laid up in one sphere affects the simplification of the other sphere. Hence, investing resources in achieving satisfaction may affect the management of work and family stressors.

The implication of COR is that the total conditions of life, and constant and severe loss of resource situations result in the development of resource conservation conditions (Hobfoll, 2001). For instance, where work stressors are high, individual employees may tend to conserve resources to cope with the stressors and this could lead to the neglect of family stressors or achievement of satisfaction.

\section{Method}

This article adopted a sequential transformative mixed methods study design. The quantitative and some qualitative data were gathered simultaneously (using a questionnaire) (Sekaran \& Bougie, 2009), and sequentially (by in-depth interviews, using semi-structured questions). However, the quantitative data was prioritised over the qualitative data (Creswell \& Garrett, 2008; Hanson, Creswell, Clark, Petska \& Creswell, 2005; Morgan, 2007). This implies that the data collected from the open-ended questions and semi-structured interview was used to substantiate the findings of the quantitative data.

\subsection{Sampling}

The targeted population was 7,000 employees with 370 professional level employees drawn conveniently from the HR, Governance, Finance and Procurement, Safety and Social Services, Infrastructure, and Human Settlement clusters of the examined Municipality in the South African Public Service. Collection of data lasted for six months. Returned and useful questionnaires were 307 in number, indicating an $84 \%$ response rate.

\subsection{Measures}

Self-report questionnaires written in English language were physically administered to the participants. SOC: the SOC-13 version of Orientation to Life Questionnaire designed by Antonovsky (1987) was used to measure SOC. The scale consists of four- items assessing meaningfulness, five items measuring comprehensibility and four other items evaluating manageability (Feldt et al., 2003). Participants responded on a 7-point semantic differential scale with dual anchoring sayings. Responses on the five items measuring comprehensibility ranked from 1) very often, to 7) very seldom or never; manageability ranked from 1) never happened to 7) always happened; and responses to meaningfulness ranked from 1) very seldom or never, to 7) very often (Feldt et al., 2003). One of the items measuring comprehensibility is: "Do you have the feeling that you are in an unfamiliar situation and do not know what to do?" An example of items assessing manageability among others is "How often do you have feelings that you're not sure you can keep under control?" The resulting score presents an individual's SOC level, while the group mean score demonstrates the respondents' level of SOC. General results of previous studies confirm the validity and reliability of the OLQ scale and give primary evidence about the worth of the core concept ( Antonovsky, 1993; Feldt et al., 2005; Feldt, Leskinen et al., 2000). The reported Cronbach's alpha from the SOC-13 in one hundred and twenty-seven (127) studies, span from 0.70 to 0.92 (Eriksson \& Lindström, 2005). The Cronbach alpha from this study is a satisfactory 0.79

Work Stressors: The Work Stressor Scale measuring job stress, absence of autonomy and function vagueness on a 29-item scale was engaged. Two items measuring job stress were adopted. Absence of autonomy was measured using Factual Autonomy Scale (FAS), a 10-item scale designed by Spector and Fox (2003) to examine the regularity of perception by the individual of restrictions of their capacity to perform their duties independently and effect certain decisions on their job. Function vagueness/role conflict was measured by using a 17-item scale adopted from a 30-item scale developed by Rizzo, House and Lirtzman (1970) to assess employees' perception about their jobs, authority, time given to perform duties, association with others, and the clarity of guidelines or policies. An item on the scale is; "I frequently feel tired and worn out during a good part of the day." Cronbach alpha reported for the work stressors scale is 0.86 Family Stressors: was measured with a Family Stressor Scale measuring parental workload/relationship tension, absence of spousal support, elder care and level of misconduct by child (ren) on a 48-item scale 
was also engaged. Eight (8) items measured parental workload/relationship tension. The items were adopted from Barling, MacEwen, Kelloway and Higginbottom (1994) and Brestan, Eyberg, Algina, Johnson, \& Boggs (2003). An item from the scale is: "how much stress does making decisions on the following decisions pose for you? (1) Supporting your child (ren)'s recreational activities versus spending time on your own career development. Response was on a five-point frequency-based answering scale (Young, Baltes \& Pratt, 2007). The Cronbach alpha for this scale was 0.98

\subsection{Data Analysis}

The IBM Statistical Package for the Social Sciences (SPSS) version 25 was used in primarily analysing the quantitative data. Subsequently, the verified data were saved as Comma Delimited $\left({ }^{*} \mathrm{CSV}\right)$ file to make it easier for ingression into the SmartPLS 3.3 software. In Partial Least Squares (PLS), construct validity, reliability and assessment of the interface between variables can be evaluated simultaneously (Barroso, Cepeda \& Rolda'n, 2010). This was done for this study (please see Table 1). The newest procedures for using PLS-SEM were observed in the appraisal and measurement models before the assessment of the structural model (Hair, Hult, Ringle, \& Sarstedt, 2013a).

Qualitative data was organised for ease of content analysis by engaging the NVIVO software.

\section{Results and Findings}

The study was of a mixed methods research design. The findings of the collected quantitative and qualitative data are as follows,

4.1 Quantitative data

The findings of the quantitative data collected for this article is as follows,

4.1.1 Age

Figure I is a bar chart presenting respondents' age distribution, examined to ensure that they were born during the apartheid era. This was done to determine if the development of strong SOC was attributable to the resources available to a person from infancy through age 30 as suggested by Antonovsky (1987). The survey was conducted in 2015, approximately twenty-one years after apartheid was eradicated in South Africa. Ninety- nine percent (99\%) of the respondents were between 26 - 65 years' age bracket.

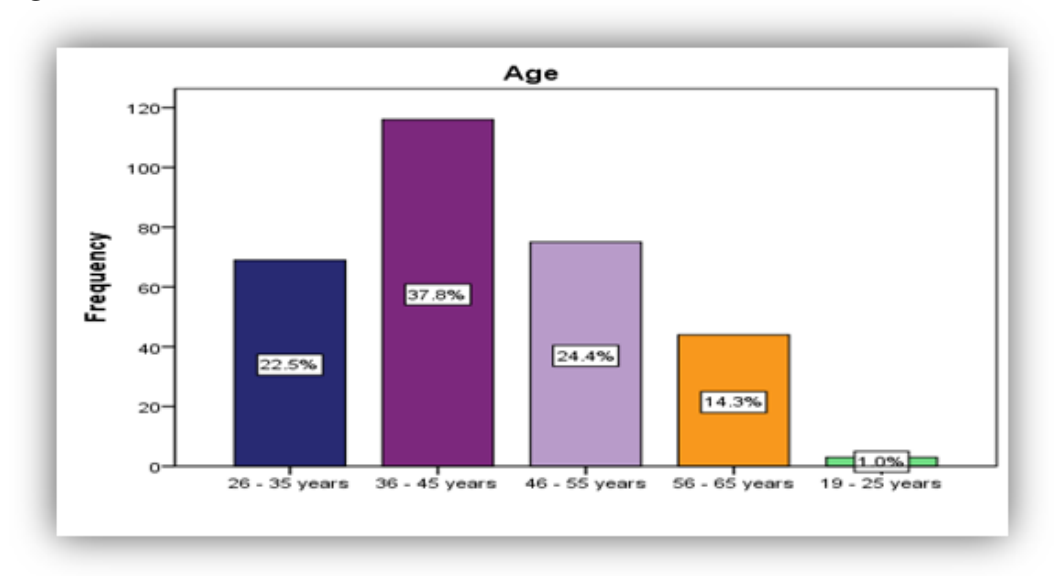

Figure 1: Bar chart presentations of respondents by age

\subsubsection{Sense of Coherence}

Figure 2 shows the mean distribution of SOC among the respondents. Clearly, employees had strong SOC as shown in the diagram. Kinman (2008) and Eriksson and Lindström (2005) agree that mean SOC at 30.66 is an indicator of strong SOC among participants. 


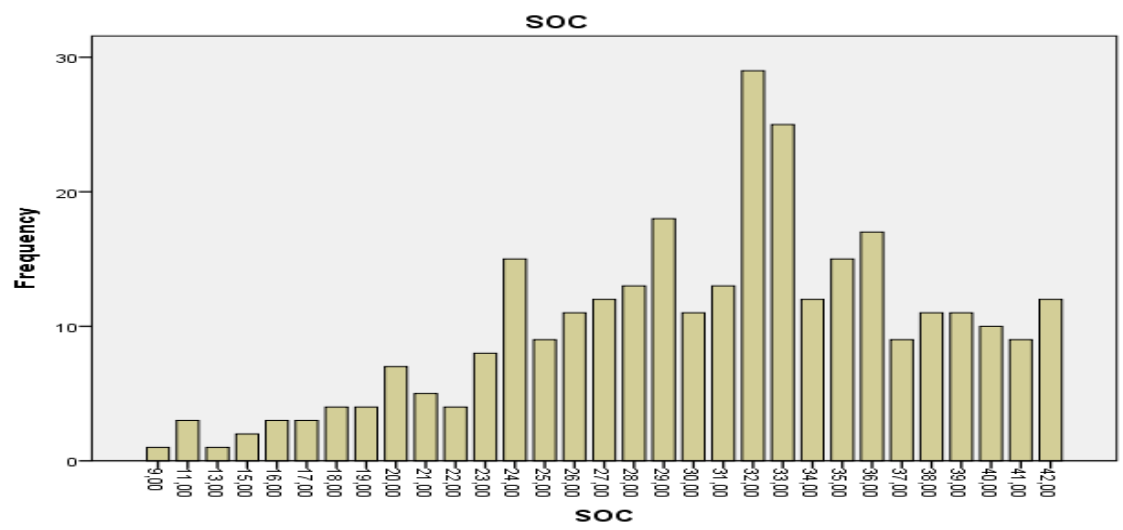

Figure 2: Mean distribution of SOC among respondents

\begin{tabular}{|c|c|c|c|c|c|}
\hline & $\begin{array}{l}\text { Original Sample } \\
\text { (O) }\end{array}$ & $\begin{array}{l}\text { Sample } \\
\text { Mean (M) }\end{array}$ & $\begin{array}{l}\text { Standard } \\
\text { Deviation } \\
\text { (STDEV) }\end{array}$ & $\begin{array}{l}\mathrm{T} \\
(\mid \mathrm{O} / \text { STDEV } \mid)\end{array}$ & P Values \\
\hline Family Stressors-> SOC & $-0,146$ & $-0,164$ & 0,043 & 3,351 & 0,001 \\
\hline Work Stressors -> SOC & $-0,400$ & 0,406 & 0,049 & 8,232 & 0,000 \\
\hline
\end{tabular}

Construct reliability and validity

In order to ascertain the significance or otherwise of the path coefficients, the bootstrapping test (please see Table 1) was conducted at; 90 case, 5,000 samples, selecting the no sign alternative (Hair, et al. 2013a; Hair et al, 2012b). The path work stressors to SOC showed a negative but statistically significant beta loading of $(\mathrm{r}=-0.400, \mathrm{p}<0.001)$, while the path family stressors to SOC was also found to be negatively significant at $(\mathrm{r}=-0.146, \mathrm{p}>0.001)$. Therefore, the findings show that negative but strong significant association exist between work and family stressors at the South African public service examined by this study.

Table 1: Construct reliability and validity

\begin{tabular}{|l|l|l|l|l|l|l|l|}
\hline & $\begin{array}{l}\text { Cronbach's } \\
\text { Alpha }\end{array}$ & rho_A & $\begin{array}{l}\text { Composite } \\
\text { Reliability }\end{array}$ & $\begin{array}{l}\text { Average } \\
\text { Variance } \\
\text { Extracted } \\
\text { (AVE) }\end{array}$ & FS & SOC & WS \\
\hline Family Stressors & 0,980 & 0,988 & 0,981 & 0,617 & 0.785 & & \\
\hline SOC & 0,796 & 0,801 & 0,859 & 0,550 & & 0.741 & \\
\hline Work Stressors & 0,862 & 0,864 & 0,890 & 0,504 & & 0.710 \\
\hline
\end{tabular}

Path coefficient of the variables

To confirm that the major indicators' internal consistency was reliable, the Cronbach alpha as well as the composite reliability coefficients were also tested (Hair, Sarstedt, Hopskins, \& Kuppelwieser, 2014). The outcomes are shown in Table 2 where the composite reliability of the measurement models is in excess of 0.859, and Cronbach alpha exceeded 0.796; indicating that the internal consistency of the variable measures are reliable. In this article, the average variance extracted (AVE) values of the variables are above the critical base value of 0.50 , thereby supporting the acceptability of the convergent validity of the measures. The evaluation of the measurement model validates the reliability and validity of the variable measures.

Table 2: Path coefficient of the variables

\subsubsection{Measurement models}

The article used the core criterion used in assessing structural model (Henseler, Ringle \& Sarstedt, 2012), i.e. the coefficient of determination R-square is 0.196 (see Fig. 3) for the outcome construct (SOC) in 
this study. This R-square of 0.196 is greater than zero and therefore validates the predictive validity of the model (Hair, Sarstedt, Ringle \& Mena, 2012b). Summarily, the predictive validity of SOC is $19.6 \%$ for this article (Hair, et al., 2012a). The reliability and validity of the measurement models were evaluated. Outer loadings lesser than 0.70 were deleted from the scale measuring family stressors and those lesser than 0.584 were dropped from the work stressor scale. However, loadings from 0.698 were accepted for the SOC scale. Although the SOC measure comprised of three dimensions measuring meaningfulness, comprehensibility and manageability, only five items (three items assessing comprehensibility and two assessing manageability) were found relevant for the study. Similarly, the work stressor scale's job stress and autonomy scales were found to be irrelevant to the study; however, the function vagueness/role conflict scale was meaningful in assessing work stressors (please see figure 3 ). This article found that the levels of reliability of the indicators were acceptable (Klarner, Sarstedt, Hoeck, \& Ringle, 2013).

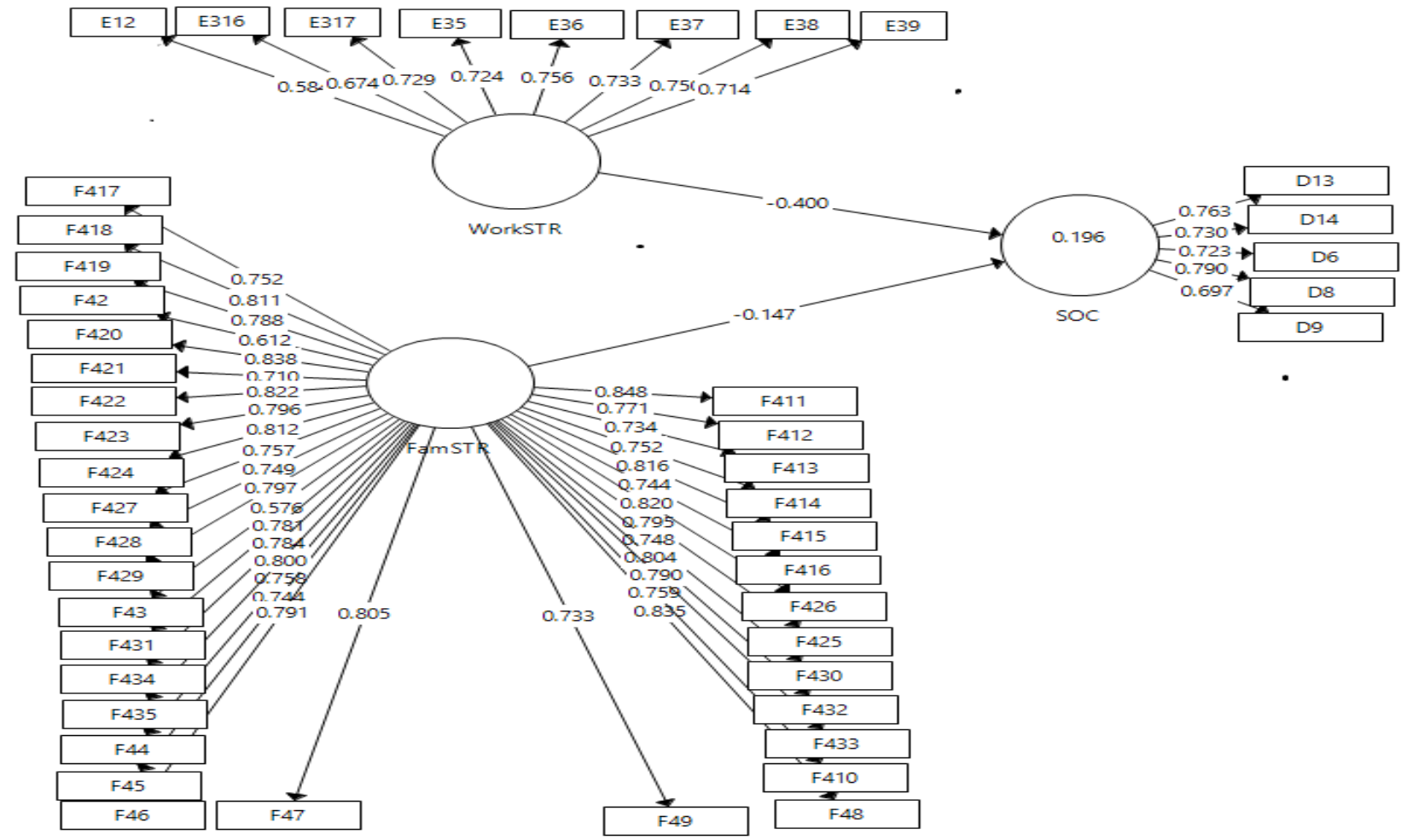

Figure 3: Structural model of constructs

\subsection{Qualitative data analysis}

SOC: The quantitative data revealed that most employees had strong SOC, while the qualitative data confirmed that the strong SOC resulted from various factors. Some of the factors include but are not limited to upbringing, religious beliefs, relational (spousal) support and fitness. Most respondents stated in response to queries about the source of their SOC are as follows,

"Yes, I believe my upbringing in part is part of the reason for me being able to cope" (Respondent 009).

"I am capable of coping with work and life stressors. I have a strong spiritual foundation which helps me cope with the trials and tribulations of life" (Respondent 071).

"Nothing much stresses me at home. I have a great child and supportive partner" (Respondent 058).

Work stressors: Most employees reported that they were facing numerous work-related stressors. Employee responses were corroborated by the feedback received from the 11 members of top management who were interviewed. The interviewees generally agreed that the employees had numerous work-stressors to contend with at the municipality. Most of them pointed at the bureaucratic structure of the municipality, career path and the impact of politics and politicians as the main causes of the high rate 
of work-stressors at the municipality. The researchers initially set out to examine three work stressors, but the qualitative data revealed many other stressors as clearly shown in Figure 3.

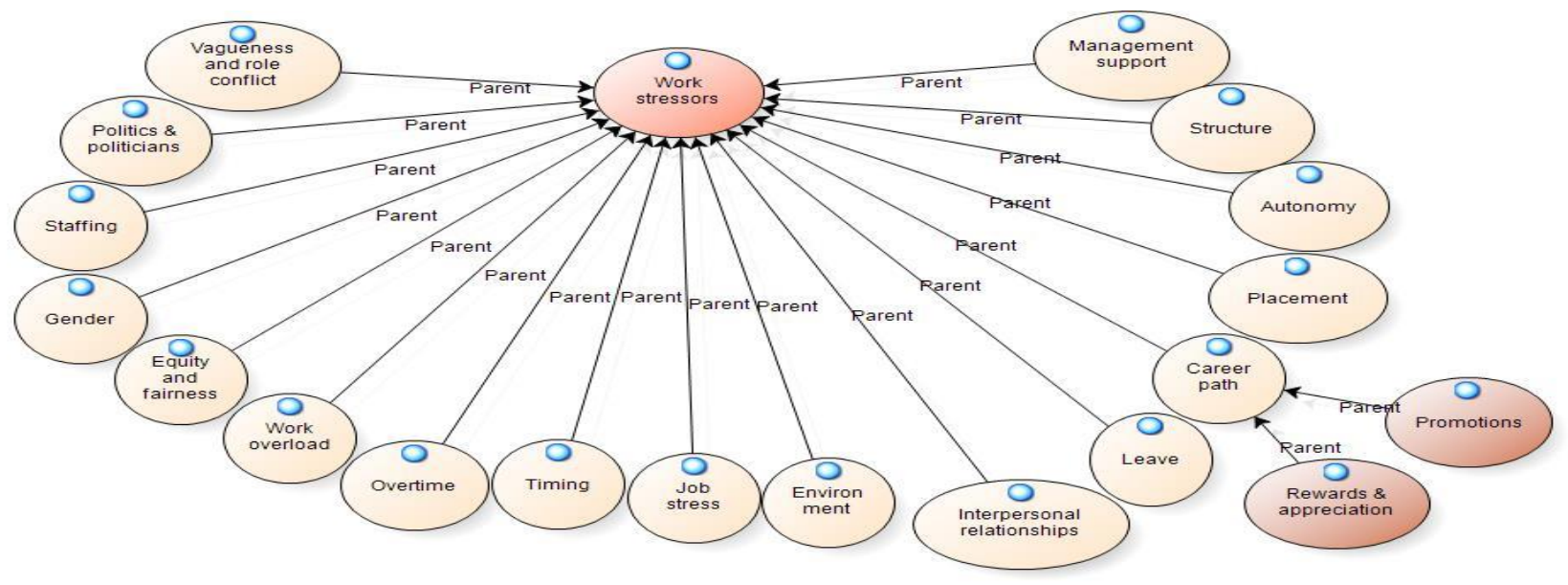

Figure 3: Notable work stressors among respondents

Family stressors: Figure 4 presents the family stressors reported by the respondents at the South African Public Service. Although employees were mostly involved with work and spent more time at work, they felt more satisfied with the family situation than their work situations. They also reasoned that work stressors interfered with their family life. It seemed that employees knew and accepted work stressor like 'working late' as a norm as shown in the following statement;

Interviewee 7: "But generally, we as auditors work under stressful circumstances that can cause conflict at home, as a result of working late hours or on weekends. This can also be a general statement, but we work beyond the official work timing."

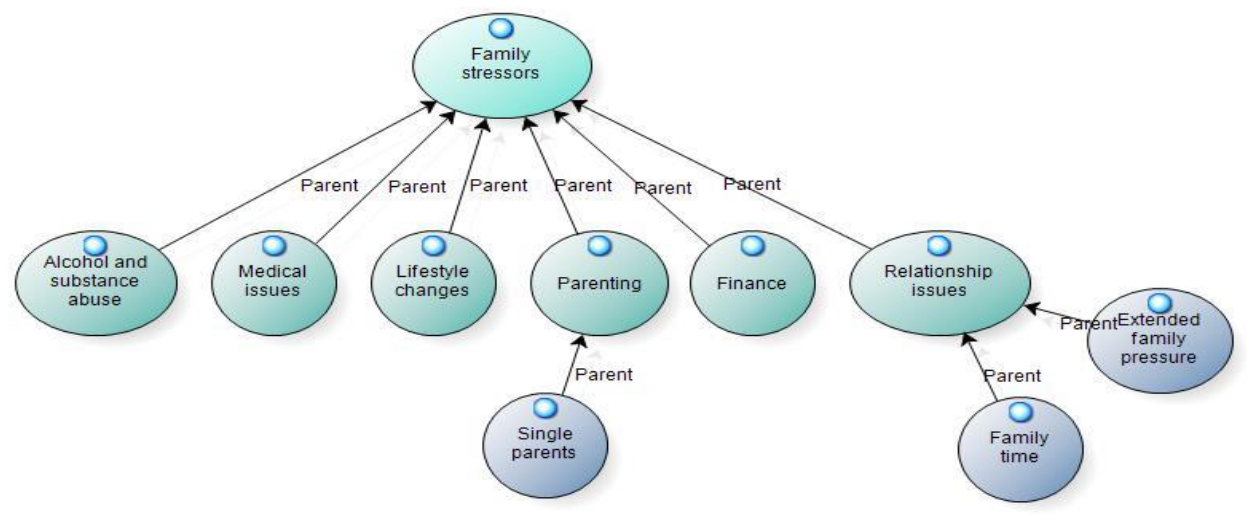

Figure 4: Pictorial presentation of family stressors found at the municipality

\subsection{Theoretical analysis}

This study found that employees were facing more work stressors than family stressors and that a significant association exists between SOC and work and family stressors. Additionally, employees were more mindful of their work stressors than family stressors through as revealed in the qualitative data analysis. Tenet 1 of COR theory suggests that the loss of resource is supreme to the individual. This study found that stressors predicted $11.8 \%$ of the discrepancy in participants' SOC. This implies that employees were losing their personal resource (SOC) to stressors. They may have utilised $11.8 \%$ of SOC in coping with stressors. Work stressors was found to be the predominant stressor; hence, Tenet 2 may have underpinned the way that employees perceived family stressors; by investing more of their SOC on handling work stressors rather than family stressors. Tenets 3 and 4 were not relative to this study as the study was only a cross-sectional one that cannot be used to measure cycles. However, the response of 
participants with respect to their appraisal and management of work and family stressors is relative to the theory's assumption that degree to which resources are laid up in one sphere affects the simplification of the other sphere.

\section{Discussion of findings}

Unexpectedly, respondents have strong SOC although they were born during the apartheid era. This is contrary to the presumption of this article which was based on Antonovsky's (1987) suggestion that adversity in the environment of upbringing from infancy through adolescence results in weak SOC. Professional level employees at the South African Public Service were found to possess strong SOC and this was supported by Kinman (2008), and Eriksson and Lindström (2005). Additionally, a significant inverse association exists between SOC and stressors in this article. This inverse relationship between stressors and SOC was supported in the literature by Wolff and Ratner (1999), Kinman (2008). Based on the COR theory (Hobfoll, 2011), the appraisal of work and family situations as stressful and potentially demanding of personal resources triggers the SOC to muster resources to constantly address the stressors and possibly conserve some of the resources for the future. This is because SOC is both a buffering factor (Antonovsky, 1993) and an inclination to survive (Strümpfer, Danana, Viviers \& Gouws, 1998). The findings could be an indication that employees used their strong SOC to address stressors which ultimately reduced the strength of individual SOC (Wolff \& Ratner, 1999). The inverse relationship found among the variables (SOC, work and family stressors) supports the assumptions of this study and the findings of Holmberg et al. (2004) and Moksnes et al. (2011), that stressors strongly and negatively impact an individual's SOC. Interestingly, this was expected, because SOC is a dispositional resource available to an individual to buffer stressors (Antonovsky, 1993). Therefore, where an individual's SOC is strong, the effect of stressors is minimal as found in the appraisal of individual employee's perception of family stressors in this study. Similarly, the absence of a strong SOC will lead to a greater impact of stressors on an individual.

Another insight is that, although the researcher presumed that work and family stressors should equally predict SOC among respondents, both jointly predicted SOC but that work stressors contributed more to the model. Hence, employees were facing more work stressors than family stressors. The qualitative data clarified this standpoint by highlighting the numerous work stressors confronting the employees at the South African Public Service. The implication of this on SOC is that, it (SOC) will consistently deplete because of the continued exposure of employees to many work stressors (Moksnes et al., 2011; Wolff \& Ratner, 1999). This article achieved its objective.

\section{Implication for practice}

This article found that most professional employees at the South African Public Service had strong SOC but were facing many work stressors. Qualitative data explained that function vagueness, job stress, role conflict, and absence of autonomy among other work stressors were confronting the employees. Reappraising the issues around bureaucracy and possibly simplifying the work environment can strategically reduce these stressors. For instance, rremoving complicated bottlenecks and practices that encumber employee focus and performance and allowing the use of simple and working technological solutions may be helpful. There is also the need to ensure that the administration 'walks the talk' about the simplification process.

Intellectuals have suggested ways of augmenting SOC through the enactment of strategies addressing work stressors especially work stressors from the source (Kinman, 2008), but research on how to maintain strong SOC has yet to be conducted by scholars. This article presents both the explored and highlighted interface between individual SOC and work and family stressors at the South African Public Service. The results having indicated that most employees have strong SOC; South African Public Service can therefore, adopt and fully support initiatives that enhance SOC. In addition, reducing function ambiguity and role conflict by clearly specifying job responsibilities and consistently adhering to the same may improve comprehensibility (Antonovsky, 1991). Creating and sustaining chances for personal development and greater involvement in decision -making by granting more control of job to employees could result in more meaningfulness and manageability with respect to the job (Kinman, 2008). 


\section{Limitations and recommendations for further studies}

This article investigated the interface between SOC and work and family stressors among professional level employees at the South African Public Service. Therefore, it is important not to generalise the findings other group of employees at the South African Public Service. Additionally, track of causality may have been compromised by the cross-sectional design of the article and reliance on the self-reporting questionnaire, though strong SOC exists among employees. A longitudinal research to gather appropriate data is recommended in order to establish the direction of causality. The use of diaries by individual employees to ascertain the effect of stressors on SOC and SOC's role in coping with work and family stressors might be an appropriate approach. This may take the study to a more thorough level of analysis. Tenets 3 and 4 of the COR theory could also be used in measuring the rapidity of gaining or losing resources (SOC in this case) in the face of continued stress. Additionally, this study could be replicated among the 'born frees' in Colleges and Universities to compare their SOC with that of those born during the apartheid era. 'Born frees' are young people born after independence in South Africa, from 1994.

\section{Conclusion}

This article brings a peculiar perspective to the study of SOC by establishing that the apartheid regime did not lead to the formation of weak SOC among the professional level employees at the South African Public Service. The article investigated the interface among SOC and work and family stressors among the participants. The 13-item version Orientation of Life Questionnaire designed Antonovsky (1987) measured SOC while work and family stressors were measured by Work Stressor Scale and Family Stressor Scale respectively. The findings of this article achieved its main objective, which was to ascertain if work and family stressors predicted SOC among professional level employees in the South African Public Service; and if the apartheid regime affected the level of SOC among employees. Employees had strong SOC, meaning that apartheid had no effect on the development of strong SOC among respondents. In addition, a statistically significant relationship was found between SOC and work and family stressors; hence work and family stressors among professional level employees at the South African Public Service predicted SOC. Based on the COR theory, it was found that employees utilised $11.8 \%$ of their SOC in addressing work and family stressors. Through the qualitative data analysis, employees were found to be more mindful of work stressors than family stressors, supporting Tenet 2 of the COR theory.

\section{References}

Abe, E.N., 2016, 'The connection between work-life balance and sense of coherence at a municipality in the South African Public Sector', PhD Thesis, School of Management, IT \& Governance, University of KwaZulu-Natal.

Antonovsky, A., 1987, Unraveling the mystery of health: How people manage stress and stay well, Jossey-Bass, University of Michigan

Antonovsky, A., 1991, The structural sources of salutogenic strengths, John Wiley \& Sons, Oxford.

Antonovsky, A., 1993, 'The structure and properties of the sense of coherence scale'. Social science $\mathcal{E}$ medicine, 36(6), 725-733.

Aseltine Jr, R. H., Gore, S., \& Gordon, J., 2000, 'Life stress, anger and anxiety, and delinquency: An empirical test of general strain theory', Journal of Health and Social Behavior, 41(3), 256-275.

Azeem, S. M., \& Akhtar, N., 2014, 'The Influence of Work Life Balance and Job Satisfaction on Organizational Commitment of Healthcare Employees'. International Journal of Human Resource Studies, 4(2), 18-24.

Barling, J., Macewen, K. E., Kelloway, E. K., \& Higginbottom, S. F., 1994, 'Predictors and outcomes of elder-care-based interrole conflict'. Psychology and Aging, 9(3), 391 -397.

Barroso, C., Cepeda, G., \& Rolda' N, J. L. 2010. Applying maximum likelihood and PLS on different sample sizes: Studies on SERVQUAL model and employee behaviour model. In V. Esposito Vinzi, W. W. Chin, J. Henseler, \& H. Wang (Eds.), Handbook of partial least squares: Concepts, methods and applications (pp. 427-447). Berlin: Springer-Verlag

Beehr, T. A., 1976, 'Perceived situational moderators of the relationship between subjective role ambiguity and role strain'. Journal of Applied Psychology, 61(1), $35-40$.

Beehr, T. A., \& Newman, J. E., 1978, 'Job stress, employee health, and organizational effectiveness; a facet analysis, model, and literature review'. Personnel psychology, 31(4), 665-699.

Brestan, E. V., Eyberg, S. M., Algina, J., Johnson, S. B., \& Boggs, S. R., 2003, 'How annoying is it? Defining parental tolerance for child misbehavior'. Child E Family Behavior Therapy, 25(2), 1-15. 
Brotheridge, C. M., \& Lee, R. T., 2005, ‘Impact of Work-Family Interference on General Well-Being: A Replication and Extension'. International Journal of Stress Management, 12(3), 203 -221.

Buchwald, P., \& Hobfoll, S. E., 2004, 'Burnout aus ressourcentheoretischer Perspektive'. Psychologie in Erziehung und Unterricht, 51(4), 247-257.

Butters, J. E., 2002, 'Family stressors and adolescent cannabis use: a pathway to problem use'. Journal of adolescence, 25(6), 645-654.

Cameron, R., 2005, 'Metropolitan restructuring (and more restructuring) in South Africa', Public Administration and Development, 25(4), 329-339.

Caplan, R. D., Cobb, S., French Jr, J. R., Harrison, R. V., \& Pinneau Jr, S. R., 1975, Job demands and worker health: Main effects and occupational difference (U.S. Department of Health, Education, and Welfare, NIOSH Publication No. 75-160), U.S. Government Printing Office, Washington, DC.

Creswell, J. W., \& Garrett, A. L., 2008, 'The" movement" of mixed methods research and the role of educators'. South African Journal of Education, 28(3), 321-333.

Diraz, T., Ortlepp, K., \& Greyling, M., 2003, 'The relationship between inter-role conflict, life satisfaction and sense of coherence in a sample of working mothers'. South African Journal of Psychology, 33(3), 191-194.

Du Toit, F. S., 2002, 'The relationship between sense of coherence, learned resourcefulness and personality type among technical personnel', Mcom Thesis, Department of Industrial Psychology, University of South Africa.

Erera, I. P., 1989, 'Role ambiguity in public welfare organizations'. Administration in Social Work, 13(2), 67-82.

Eriksson, M., \& Lindström, B., 2007, 'Antonovsky's sense of coherence scale and its relation with quality of life: a systematic review'. Journal of Epidemiology and community health, 61 (11), 938-944.

Eriksson, M., \& Lindström, B., 2005, 'Validity of Antonovsky's sense of coherence scale: a systematic review'. Journal of Epidemiology and community health, 59(6), 460-466.

Feldt, T., Leskinen, E., Kinnunen, U. And Ruoppila, I., 2003. 'The stability of sense of coherence: Comparing two age groups in a 5-year follow-up study'. Personality and Individual Differences, 35(5), 1151-1165.

Fisher, C. D., \& Gitelson, R., 1983, 'A meta-analysis of the correlates of role conflict and ambiguity'. Journal of Applied Psychology, 68(2), 320-333.

Freedy, J. R., \& Hobfoll, S. E., 1994, 'Stress inoculation for reduction of burnout: A conservation of resources approach'. Anxiety, Stress and Coping, 6(4), 311-325.

Freedy, J. R., Hobfoll, S. E., \& Ribbe, D. P., 1994, 'Life events, war and adjustment: Lessons for the Middle East', Anxiety, stress, and coping, 7(3), 191-203.

French, J. R., \& Caplan, R. D., 1972, 'Organizational stress and individual strain: The failure of success, Amacom New York, 30, 66.

Hair Jr, J.F., Sarstedt, M., Hopkins, L. \& Kuppelwieser, V.G. 2014. Partial least squares structural equation modeling (PLS-SEM): An emerging tool in business research. European Business Review, 26(2), 106-121.

Hair, J.F., Hut, G.T.M., Rangel, C.M., \& Sorted, M. 2013a. A Primer on Partial Least Squares Structural Equation Modeling (PLS-SEM). Sage, Thousand Oaks.

Halbesleben, J. R., \& Bowler, W. M., 2007, 'Emotional exhaustion and job performance: the mediating role of motivation', Journal of Applied Psychology, 92(1), 93-106.

Hackman, J. R., \& Oldham, G. R.., 1976, 'Motivation through the design of work: Test of a theory'. Organizational Behavior and Human Performance, 16(2), 250-279.

Hamner, W. C., \& Tosi, H. L., 1974. 'Relationship of role conflict and role ambiguity to job involvement measures'. Journal of Applied Psychology, 59(4), 497-499.

Hanson, W. E., Creswell, J. W., Clark, V. L. P., Petska, K. S., \& Creswell, J. D., 2005, 'Mixed methods research designs in counseling psychology', Journal of counseling psychology, 52(2), 224-235.

Henseler, J., Ringle, C.M., \& Sarstedt, M. 2012. Using partial least squares path modeling in international advertising research: basic concepts and recent issues. In: Okazaki, S. (Ed.), Handbook of Research in International Advertising. Edward Elgar Publishing, Cheltenham, pp. 252e276.

Hepburn, C. G., \& Barling, J., 1996, 'Eldercare responsibilities, interrole conflict, and employee absence: a daily study'. Journal of Occupational Health Psychology, 1(3), 311-318.

Hershcovis, M. S., Turner, N., Barling, J., Arnold, K. A., Dupré, K. E., Inness, M., . . Sivanathan, N., 2007, ‘Predicting workplace aggression: a meta-analysis'. Journal of Applied Psychology, 92(1), 228-238.

Hobfoll, S. E., 1989, 'Conservation of resources: A new attempt at conceptualizing stress', American psychologist, 44(3), 513-524.

Hobfoll, S. E., 2001, 'The influence of culture, community, and the nested-self in the stress process: advancing conservation of resources theory'. Applied Psychology, 50(3), 337-421.

Hobfoll, S. E., 2011a, 'Conservation of resource caravans and engaged settings', Journal of Occupational and Organizational Psychology, 84(1), 116-122. 
Hobfoll, S. E. 2011b. Conservation of resources theory: Its implication for stress, health, and resilience. The Oxford handbook of stress, health, and coping, Oxford University Press, New York

Holmberg, S., Thelin, A., \& Stiernström, E. L., 2004, 'Relationship of Sense of Coherence to Other Psychosocial Indices'. European Journal of Psychological Assessment, 20(4), 227 - 236.

Hosie, P. J., \& Sevastos, P. P., 2010, 'A framework for conceiving of job-related affective wellbeing'. Management Revue, 21(4), 406-436.

House, R. J., \& Rizzo, J. R., 1972, 'Role conflict and ambiguity as critical variables in a model of organizational behavior' Organizational Behavior and Human Performance, 7(3), 467-505.

Jackson, S. E., \& Schuler, R. S., 1985, 'A meta-analysis and conceptual critique of research on role ambiguity and role conflict in work settings', Organizational Behavior and Human Decision Processes, 36(1), 16-78.

Jamal, M., 2005, 'Personal and organizational outcomes related to job stress and Type-A behavior: a study of Canadian and Chinese employees'. Stress and Health, 21(2), 129-137.

Jawahar, I., Stone, T. H., \& Kisamore, J. L., 2007, 'Role conflict and burnout: The direct and moderating effects of political skill and perceived organizational support on burnout dimensions'. International Journal of Stress Management, 14(2), 142-159.

Jones, F., Burke, R. J., \& Westman, M., 2013, Work-life balance: a psychological perspective. Psychology Press, New York.

Jones, F., Burke, R.J., Westman, M., Jones, F., Burke, R.J. And Westman, M., 2006, 'Work-life balance: key issues'. Work-life balance: A psychological perspective, Psychology Press, East Sussex.

Kahn, R. L., Wolfe, D. M., Quinn, R. P., Snoek, J. D., \& Rosenthal, R. A., 1964, Organizational stress: Studies in role conflict and ambiguity, John Wiley, Oxford

Kim, H., \& Stoner, M., 2008, 'Burnout and turnover intention among social workers: Effects of role stress, job autonomy and social support'. Administration in Social Work, 32(3), 5-25.

Kinman, G., 2008, 'Work stressors, health and sense of coherence in UK academic employees', Educational Psychology, 28(7), 823-835.

Kivimäki, M., Feldt, T., Vahtera, J., \& NURMI, J.E., 2000, 'Sense of coherence and health: evidence from two crosslagged longitudinal samples', Social science E medicine, 50(4), 583-597.

Klarner, P., Sarstedt, M., Hoeck, M., \& Ringle, C. M. 2013. Disentangling the effects of team competences, team adaptability, and client communication on the performance of management consulting teams. Long Range Planning, 46(3), 258-286.

Liu, C., Spector, P., \& Jex, S., 2005, 'The relation of job control with job strains: A comparison of multiple data sources'. Journal of Occupational and Organizational Psychology, 78(3), 325-336.

Mattila, M.L., Rautava, P., Honkinen, P.L., Ojanlatva, A., Jaakkola, S., Aromaa, M., Suominen, S., Helenius, H. \& Sillanpää, M., 2011, 'Sense of coherence and health behaviour in adolescence'. Acta Paediatrica, 100(12), 15901595.

May, J., \& Govender, J., 1998, 'Poverty and inequality in South Africa'. Indicator South Africa, presented at Centre for Social and Development Studies, University of Natal.

Mc Cubbin, H. I., \& Sussman, M. B., 2014, Social Stress and the Family: Advances and Developments in Family Stress Therapy and Research, Routledge, New York.

Mcgrath, J. E., 1976, Stress and behavior in organizations. Handbook of industrial and organizational psychology, 1351, 1396.

Merikangas, K. R., Dierker, L., \& Fenton, B., 1998, Familial factors and substance abuse: Implications for prevention a case study in Ashery, Robertson \& Kumpfer (eds.) NIDA Res Monograph, 177, pp. 12-41, Rockville, MD.

Miraftab, F., 2004., Invited and invented spaces of participation: Neoliberal citizenship and feminists' expanded notion of politics (Vol. 1). Bloomington, Indiana University Press.

Moksnes, U. K., Rannestad, T., Byrne, D. G., \& Espnes, G. A., 2011, 'The association between stress, sense of coherence and subjective health complaints in adolescents: sense of coherence as a potential moderator', Stress and Health, 27(3), e157-e165.

Moos, R., 2013, Coping with life crises: An integrated approach, Plenum Press, New York.

Morgan, D. L., 2007, ‘Paradigms lost and pragmatism regained methodological implications of combining qualitative and quantitative methods'. Journal of mixed methods research, 1(1), 48-76.

Morris, J. H., Steers, R. M., \& Koch, J. L., 1979, ‘Influence of Organization Structure on Role Conflict and Ambiguity for Three Occupational Groupings'. Academy of Management Journal, 22(1) 58-71.

Netemeyer, R. G., Johnston, M. W., \& Burton, S., 1990, 'Analysis of role conflict and role ambiguity in a structural equations framework'. Journal of Applied Psychology, 75(2), 148-157.

Neveu, J. P., 2007, 'Jailed resources: Conservation of resources theory as applied to burnout among prison guards', Journal of Organizational Behavior, 28(1), 21-42.

Nicholson, P. J., \& Goh, S. C., 1983, 'The relationship of organization structure and interpersonal attitudes to role conflict and ambiguity in different work environments', Academy of Management Journal, 26(1), 148-155. 
Nielsen, A.M. \& Hansson, K., 2007, 'Associations between adolescents' health, stress and sense of coherence'. Stress and Health, 23(5), 331-341.

Özler, B., 2007. 'Not Separate, Not Equal: Poverty and Inequality in Post-apartheid South Africa'. Economic Development and Cultural Change, 55(3), 487-529.

Pandey, S. K., \& Wright, B. E., 2006, 'Connecting the dots in public management: political environment, organizational goal ambiguity, and the public manager's role ambiguity'. Journal of Public Administration Research and Theory, 16(4), 511-532.

Parker, S. K., Axtell, C. M., \& Turner, N., 2001, 'Designing a safer workplace: Importance of job autonomy, communication quality, and supportive supervisors'. Journal of Occupational Health Psychology, 6(3), $211-228$.

Ramaswami, S. N., Agarwal, S., \& Bhargava, M., 1993, 'Work alienation of marketing employees: influence of task, supervisory, and organizational structure factors', Journal of the Academy of Marketing Science, 21(3), 179-193.

Richardson, C.G. \& Ratner, P.A., 2005, 'Sense of coherence as a moderator of the effects of stressful life events on health', Journal of epidemiology and community health, 59(11), 979-984.

Rivera, F., García-Moya, I., Moreno, C., \& Ramos, P., 2013, ‘Developmental contexts and sense of coherence in adolescence: A systematic review'. Journal of health psychology, 18(6), 800-812.

Rizzo, J. R., House, R. J., \& Lirtzman, S. I., 1970, 'Role conflict and ambiguity in complex organizations'. Administrative science quarterly, 15(2), 150-163.

Ryland, E. \& Greenfield, S., 1991, 'Work stress and well being: An investigation of Antonovsky's sense of coherence model'. Journal of Social Behavior and Personality, 6(7), 39.

Sarenmalm, E. K., Browall, M., Persson, L. O., Fall-Dickson, J., \& Gaston-Johansson, F., 2013, 'Relationship of sense of coherence to stressful events, coping strategies, health status, and quality of life in women with breast cancer'. Psycho-Oncology, 22(1), 20-27.

Sekaran, U., \& Bougie, R., 2009, Research methods of business: A skill-building approach, John Wiley \& Sons Inc, New York.

Selye, H. 1975. 'Confusion and controversy in the stress field'. Journal of human stress, 1(2), 37-44.

Shore, B. 1996. Culture in mind: Cognition, culture, and the problem of meaning, Oxford University Press, England.

Spector, P. E., \& Fox, S., 2003, 'Reducing subjectivity in the assessment of the job environment: Development of the Factual Autonomy Scale (FAS)', Journal of Organizational Behavior, 24(4), 417-432.

Strümpfer, D., Danana, N., Gouws, J., \& Viviers, M., 1998, 'Personality dispositions and job satisfaction', South African Journal of Psychology, 28(2), 92-100.

Tavora, I., 2012, 'The southern European social model: familialism and the high rates of female employment in Portugal'. Journal of European Social Policy, 22(1), 63-76.

Thompson, C. A., \& Prottas, D. J., 2006, 'Relationships among organizational family support, job autonomy, perceived control, and employee well-being', Journal of Occupational Health Psychology, 11(1), 100-118.

Voydanoff, P., 2004, 'The effects of work demands and resources on work-to-family conflict and facilitation'. Journal of Marriage and Family, 66(2), 398-412.

Warr, P., 2007. 'Searching for happiness at work', Psychologist-Leicester, 20(12), 726-729.

Wolff, A. C., \& Ratner, P. A., 1999, 'Stress, social support, and sense of coherence', Western Journal of Nursing Research, 21(2), 182-197.

Young, L.M., Baltes, B.B. \& Pratt, A.K., 2007, ‘Using selection, optimization, and compensation to reduce job/family stressors: Effective when it matters', Journal of Business and Psychology, 21(4), 511-539.

Yozgat, U., Yurtkoru, S., \& Bilginoğlu, E., 2013, 'Job stress and job performance among employees in public sector in Istanbul: Examining the moderating role of emotional intelligence'. Procedia-Social and behavioral sciences, 75 , 518-524.

Zellars, K. L., Perrewé, P. L., Hochwarter, W. A., \& Anderson, K. S., 2006, 'The interactive effects of positive affect and conscientiousness on strain', Journal of Occupational Health Psychology, 11(3), 281-289. 